\title{
Association of Immediate Postoperative Temperature in the Surgical Intensive Care Unit with 1-Year Mortality: Retrospective Analysis Using Digital Axillary Thermometers
}

\author{
Jiwook Kim ${ }^{1 *}$, Tak Kyu Oh²*, Jaebong Lee ${ }^{3}$, Saeyeon Kim², In-Ae Song ${ }^{2}$ \\ ${ }^{1}$ Department of Anesthesiology and Pain Medicine, Kosin University College of Medicine, Busan; ${ }^{2}$ Department of Anesthesiology and Pain Medicine and \\ ${ }^{3}$ Medical Research Collaborating Center, Seoul National University Bundang Hospital, Seongnam, Korea
}

Background: Postoperative body temperature is closely associated with prognosis although there is limited research regarding this association at postoperative intensive care unit (ICU) admission. Furthermore, no studies have used digital axillary thermometers to measure postoperative body temperature. This study investigated the association between mortality and postoperative temperature measured using a digital axillary thermometer within 10 minutes after ICU admission.

Methods: This retrospective observational study evaluated data from adult patients admitted to an ICU after elective or emergency surgery. The primary outcome was 1-year mortality after ICU admission. Multivariable logistic regression analysis with restricted cubic splines was used to evaluate the association between temperature and outcomes.

Results: We evaluated data from 5,868 patients admitted between January 1, 2013 and May 31,2016 , including 5,311 patients (90.5\%) who underwent noncardiovascular surgery and 557 patients $(9.5 \%)$ who underwent cardiovascular surgery. Deviation from the median temperature $\left(36.6^{\circ} \mathrm{C}\right)$ was associated with increases in 1-year mortality $\left(\leq 36.6^{\circ} \mathrm{C}\right.$ : linear coefficient, $-0.531 ; \mathrm{P}<0.001$ and $\geq 36.6^{\circ} \mathrm{C}$ : spline coefficient, $\left.0.756 ; \mathrm{P}<0.001\right)$. Similar statistically significant results were observed in the noncardiovascular surgery group, but not in the cardiovascular surgery group.

Conclusions: An increase or decrease in body temperature (vs. $36.6^{\circ} \mathrm{C}$ ) measured using digital axillary thermometers within 10 minutes of postoperative ICU admission was associated with increased 1-year mortality. However, no significant association was observed after cardiovascular surgery. These results suggest that postoperative temperature is associated with longterm mortality in patients admitted to the surgical ICU in the postoperative period.

Key Words: critical care; intensive care units; temperature

\section{INTRODUCTION}

Body temperature is routinely measured during the postoperative period [1], as postoperative hypothermia is a common complication associated with poor outcomes [2-4]. A $1^{\circ} \mathrm{C}-3^{\circ} \mathrm{C}$

\section{Original Article}

Received: August 10, 2018

Revised: November 8, 2018

Accepted: November 27, 2018

Corresponding author

In-Ae Song

Department of Anesthesiology and Pain Medicine, Seoul National University Bundang Hospital, 82 Gumi-ro 173beon-gil, Bundang-gu, Seongnam 13620, Korea

Tel: +82-31-787-7499

Fax: +82-31-787-4063

E-mail: songoficu@outlook.kr

*The first two authors contributed equally to this study.

Copyright (@ 2019 The Korean Society of Critical Care Medicine

This is an Open Access article distributed under the terms of Creative Attributions Non-Commercial License (http:// creativecommons.org/li-censes/by-nc/4.0/) which permits unrestricted noncommercial use, distribution, and reproduction in any medium, provided the original work is properly cited. 
decrease in tympanic temperature is associated with an increased complication rate, which can be reduced through active rewarming $[5,6]$. Postoperative hyperthermia may also be associated with adverse postoperative outcomes [7] and infection [1]. Patients admitted to the intensive care unit (ICU) after surgery have relatively severe conditions and it is critical to control their body temperature. Of the patients entering the ICU after surgery, $57.1 \%$ are exposed to core hypothermia [8] and, in this setting, hypothermia (mean temperature $<36^{\circ} \mathrm{C}$ for 24 hours) is associated with in-hospital mortality [9].

Furthermore, body temperature changes continuously within a broad range $\left(30^{\circ} \mathrm{C}-40^{\circ} \mathrm{C}\right)$, which can influence outcomes based on the specific definitions of hypothermia and hyperthermia $[8,10]$. This study evaluated the association between mortality and postoperative body temperature measured using a digital axillary thermometer immediately after ICU admission. To evaluate general trends, we did not specifically define hypothermia/hyperthermia, and instead evaluated associations based on the distribution of body temperatures.

\section{MATERIALS AND METHODS}

The protocol for this retrospective observational study was approved by the Institutional Review Board of Seoul National University Bundang Hospital (SNUBH; IRB No. B-1806/474105). Medical records were obtained for adult patients ( $\geq 19$ years old) who were admitted to an ICU after undergoing elective or emergency surgery at SNUBH between January 1, 2013 and May 31, 2016. Only the last ICU admission was counted for patients who underwent multiple surgeries and ICU admissions. The exclusion criteria were: (1) inaccurate medical records, (2) death within 1 hour of ICU admission, (3) body temperature not measured using an axillary thermometer, and (4) interval between operating room discharge and ICU admission > 15 minutes (e.g., patients who underwent computed tomography before ICU admission). SNUBH is a 1,360-bed tertiary care hospital with 102 beds in four ICUs (a medical ICU, a surgical ICU, and two emergency ICUs); approximately 150 surgeries per day are performed in 36 operating rooms. All patient records have been managed since 2003 using an electronic medical record system.

\section{Measurements and Outcomes}

The following data were collected: type of surgery, age (years), body mass index $\left(\mathrm{kg} / \mathrm{m}^{2}\right)$, cancer status, history of emergency surgery, American Society of Anaesthesiologists classification,

\section{KEY MESSAGES}

- One-year mortality increases when body temperature increases or decreases (vs. $36.6^{\circ} \mathrm{C}$ ) among postoperative patients after intensive care unit (ICU) admission.

- This trend was not observed among patients who underwent cardiovascular surgery.

- The results suggest that postoperative temperature is associated with long-term mortality among patients admitted to the surgical ICU in the postoperative period.

operation time (minute), body temperature $\left({ }^{\circ} \mathrm{C}\right)$, albumin level (g/dl), creatinine level (mg/dl), hemoglobin concentration $(\mathrm{g} / \mathrm{dl})$, platelet count $(/ \mu \mathrm{l})$, prothrombin time-international normalized ratio, and white blood cell count $(/ \mu \mathrm{l})$. The patients' temperatures were measured within 10 minutes of ICU admission using a digital axillary thermometer (ET*C205S; Terumo Corporation, Tokyo, Japan). Body temperature was measured in a single axilla by trained ICU nurses in accordance with a set protocol, and the measurement was repeated in the other axilla if the initial measurement was inaccurate. The mean temperature was recorded if measurements were performed more than twice based on suspicion of abnormal body temperature. The minimum values of the laboratory test results after ICU admission were recorded. Cardiac or major vascular surgeries using cardiopulmonary bypass were classified as cardiovascular surgeries; all other procedures were classified as noncardiovascular surgeries. The primary outcome was 1-year mortality after ICU admission. We also examined this association according to whether the patients underwent cardiovascular or noncardiovascular surgery.

\section{Statistical Analysis}

Continuous variables were reported as mean and standard deviation or median (range), and categorical variables were reported as number and percentage. Intergroup comparisons of 1-year mortality were performed using Student t-test and the chi-square test. The relationship between body temperature and 1-year mortality was analyzed after dividing the body temperatures using three knots ( $10 \%$, median, and $90 \%)$. We then performed univariable logistic regression analyses with restricted cubic splines (RCS) at each of the continuous intervals between the knots ( $10 \%$ to median and median to $90 \%$ ). Multivariable logistic regression analysis was performed using an RCS model that was fit with covariates that had P-values $<0.1$, and the analysis was adjusted for covariates that were fit in the univariable analysis [11]. Statistical significance was set 
at $\mathrm{P}<0.05$, and analyses were performed using IBM SPSS ver. 23.0 (IBM Corp., Armonk, NY, USA) and R software ver. 3.3.2 with R packages (R Foundation for Statistical Computing, Vienna, Austria).

\section{RESULTS}

\section{Patients}

A total of 8,198 cases were admitted to the ICUs after surgical procedures between January 1, 2013 and May 31, 2016. Among

Table 1. Baseline and demographic characteristics of postoperative patients in the ICU

\begin{tabular}{|c|c|c|}
\hline Variable & Value & Median (range) \\
\hline \multicolumn{3}{|l|}{ Operation } \\
\hline Noncardiovascular surgery & 90.5 & \\
\hline Cardiovascular surgery & 9.5 & \\
\hline Age (yr) & $61.51 \pm 15.50$ & $63.0(19.0-97.0)$ \\
\hline Height (cm) & $162.13 \pm 9.13$ & $162.5(123.0-195.3)$ \\
\hline Weight (kg) & $62.68 \pm 12.64$ & $61.7(24.3-160.0)$ \\
\hline $\mathrm{BMI}\left(\mathrm{kg} / \mathrm{m}^{2}\right)$ & $23.76 \pm 3.80$ & $23.6(12.2-55.4)$ \\
\hline \multicolumn{3}{|l|}{ Cancer } \\
\hline No & 65.9 & \\
\hline Yes & 34.1 & \\
\hline \multicolumn{3}{|l|}{ Emergency operation } \\
\hline No & 82.6 & \\
\hline Yes & 17.4 & \\
\hline \multicolumn{3}{|l|}{ ASA class } \\
\hline 1 & 12.8 & \\
\hline 2 & 52.7 & \\
\hline 3 & 32.6 & \\
\hline $4+5+6$ & 1.9 & \\
\hline Operation time (min) & $235.57 \pm 140.81$ & $220.0(5.0-1,050.0)$ \\
\hline Body temperature $\left({ }^{\circ} \mathrm{C}\right)^{\mathrm{a}}$ & $36.62 \pm 0.78$ & $36.6(28.9-39.8)$ \\
\hline Albumin (g/dl) & $3.14 \pm 0.69$ & $3.1(1.4-5.0)$ \\
\hline Creatinine (mg/dl) & $1.16 \pm 1.58$ & $0.80(0.15-18.46)$ \\
\hline Hemoglobin (g/dl) & $11.10 \pm 2.02$ & $11.0(5.0-17.4)$ \\
\hline Platelet count $\left(\times 10^{3} / \mu \mathrm{l}\right)$ & $182.87 \pm 91.61$ & $168.5(7.0-821.0)$ \\
\hline Prothrombin time (INR) & $1.30 \pm 0.38$ & $1.20(0.84-5.27)$ \\
\hline White blood cell count $\left(\times 10^{3} / \mu \mathrm{l}\right)$ & $10.99 \pm 6.02$ & $10.06(0.30-70.30)$ \\
\hline
\end{tabular}

Values are presented as percent (total number $=5,868$ ) or mean \pm standard deviation.

ICU: intensive care unit; BMI: body mass index; ASA: American Society of Anaesthesiologists; INR: international normalized ratio.

a Body temperature was defined as the first temperature measured using a digital axillary thermometer within 10 minutes of entry into the intensive care unit. them, 1,028 cases were omitted because of two or more postoperative ICU admissions for single patients; only the last postoperative ICU admission was considered in the analysis. An additional 1,302 cases were also excluded because of patient age $\leq 18$ years (477 patients), inaccurate data regarding operation time or ICU admission timing (91 patients), axillary temperature not measured within 10 minutes of ICU admission (617 patients), non-axillary temperature measurements (94 patients), death within 1 hour of ICU admission (six patients), and not being immediately admitted to the ICU (17 patients). Thus, 5,868 patients were included in the final analysis.

Table 1 summarizes the patients' characteristics. Noncardiovascular surgery was performed for 5,311 patients (90.5\%) and cardiovascular surgery was performed for 557 patients (9.5\%). Table 2 summarizes the patients' characteristics according to surgery type and mortality 1 year after ICU admission. No significant differences were observed in the axillary temperatures of patients who died within 1 year or survived to 1 year (survival, $36.62^{\circ} \mathrm{C} \pm 0.52^{\circ} \mathrm{C}$ vs. death, $36.61^{\circ} \mathrm{C} \pm 0.88^{\circ} \mathrm{C}$; $\mathrm{P}=0.683$ ). The same results were observed for the noncardiovascular surgery $(\mathrm{P}=0.661)$, and cardiovascular surgery $(\mathrm{P}=0.061)$ groups.

\section{Multivariable Regression Model with RCS for 1-Year Mortality}

The RCS between 1-year mortality and the initial postoperative axillary temperature in the ICU is shown according to surgical type in Figure 1. The three temperature knots were $36.0^{\circ} \mathrm{C}$ for $10 \%, 36.6^{\circ} \mathrm{C}$ for the median, and $37.2^{\circ} \mathrm{C}$ for $90 \%$. The 1 -year mortality rate tended to increase in both noncardiovascular and cardiovascular surgery groups as the postoperative body temperature decreased from $36.6^{\circ} \mathrm{C}$. However, when the postoperative body temperature increased to more than $36.6^{\circ} \mathrm{C}$, the 1-year mortality tended to increase in the noncardiovascular surgery group, but not in the cardiovascular surgery group.

Supplementary Table 1 shows the results of univariable logistic regression analysis with RCS for 1-year mortality, and Table 3 shows the results of the multivariable logistic regression analysis with RCS for 1-year mortality after adjusting for covariates. Overall, increases or decreases in temperature relative to the median $\left(36.6^{\circ} \mathrm{C}\right)$ were associated with increased 1 -year mortality $\left(\leq 36.6^{\circ} \mathrm{C}\right.$ : linear coefficient, $-0.531, \mathrm{P}<0.001$; $\geq 36.6^{\circ} \mathrm{C}$ : spline coefficient, $0.756, \mathrm{P}<0.001$ ). A similar trend with larger coefficients was observed in the noncardiovascular surgery group $\left(\leq 36.6^{\circ} \mathrm{C}\right.$ : linear coefficient, $-0.701, \mathrm{P}<0.001$; 
Table 2. One-year mortality after postoperative admission to the intensive care unit

\begin{tabular}{|c|c|c|c|c|c|c|c|c|c|}
\hline \multirow[b]{2}{*}{ Variable } & \multicolumn{3}{|c|}{ All patients $(n=5,868)$} & \multicolumn{3}{|c|}{ Noncardiovascular surgery $(n=5,311)$} & \multicolumn{3}{|c|}{ Cardiovascular surgery $(n=557)$} \\
\hline & $\begin{array}{l}\text { 1-Year } \\
\text { survival }\end{array}$ & $\begin{array}{l}\text { 1-Year } \\
\text { death }\end{array}$ & P-value & $\begin{array}{l}\text { 1-Year } \\
\text { survival }\end{array}$ & $\begin{array}{l}\text { 1-Year } \\
\text { death }\end{array}$ & P-value & $\begin{array}{l}\text { 1-Year } \\
\text { survival }\end{array}$ & $\begin{array}{l}\text { 1-Year } \\
\text { death }\end{array}$ & P-value \\
\hline Age (yr) & $60.54 \pm 15.45$ & $68.27 \pm 14.11$ & $<0.001$ & $60.27 \pm 15.58$ & $68.04 \pm 14.43$ & $<0.001$ & $63.08 \pm 13.92$ & $70.75 \pm 9.96$ & $<0.001$ \\
\hline BMI $\left(\mathrm{kg} / \mathrm{m}^{2}\right)$ & $23.99 \pm 3.79$ & $22.06 \pm 3.47$ & $<0.001$ & $23.97(3.80)$ & $22.00(3.51)$ & $<0.001$ & $24.19 \pm 3.69$ & $22.77 \pm 2.96$ & 0.001 \\
\hline Cancer & 30.6 & 58.7 & $<0.001$ & 33.5 & 64.1 & $<0.001$ & 2.8 & 1.6 & 1.000 \\
\hline Emergency surgery & 15.8 & 28.2 & $<0.001$ & 16.2 & 28.0 & $<0.001$ & 11.8 & 31.3 & $<0.001$ \\
\hline ASA class & & & $<0.001$ & & & $<0.001$ & & & 0.002 \\
\hline 1 & 14.0 & 4.5 & & 15.6 & 5.0 & & 0.7 & 0 & \\
\hline 2 & 53.4 & 47.5 & & 56.5 & 51.3 & & 28.0 & 9.4 & \\
\hline 3 & 31.0 & 44.0 & & 26.6 & 40.6 & & 66.9 & 77.4 & \\
\hline $4+5+6$ & 1.6 & 4.0 & & 1.2 & 3.1 & & 4.4 & 13.2 & \\
\hline Body temperature $\left({ }^{\circ} \mathrm{C}\right)^{\mathrm{a}}$ & $36.62 \pm 0.52$ & $36.61 \pm 0.88$ & 0.683 & $36.63 \pm 0.50$ & $36.65 \pm 0.81$ & 0.661 & $36.50 \pm 0.65$ & $36.18 \pm 1.31$ & 0.061 \\
\hline Albumin $<3 \mathrm{~g} / \mathrm{dl}$ & 31.8 & 57.1 & $<0.001$ & 33.4 & 58.0 & $<0.001$ & 18.8 & 48.2 & $<0.001$ \\
\hline Creatinine $>1.3 \mathrm{mg} / \mathrm{dl}$ & 10.5 & 23.4 & $<0.001$ & 10.0 & 21.2 & $<0.001$ & 14.7 & 45.6 & $<0.001$ \\
\hline $\mathrm{Hb}(\mathrm{g} / \mathrm{dl})$ & $11.24 \pm 1.94$ & $10.49 \pm 1.97$ & $<0.001$ & $11.05 \pm 1.54$ & $10.62 \pm 1.72$ & $<0.001$ & $10.94 \pm 1.75$ & $10.01 \pm 1.94$ & $<0.001$ \\
\hline Platelet $<100,000 / \mu l$ & 9.0 & 16.8 & $<0.001$ & 7.5 & 15.6 & $<0.001$ & 21.7 & 29.3 & 0.252 \\
\hline PT $>1.3$ INR & 23.5 & 43.7 & $<0.001$ & 18.8 & 40.1 & $<0.001$ & 59.9 & 76.4 & 0.026 \\
\hline $\begin{array}{l}\text { White blood cell } \\
\text { count }>10,000 / \mu l\end{array}$ & 48.3 & 54.1 & 0.006 & 47.1 & 53.6 & 0.003 & 58.6 & 58.6 & 1.000 \\
\hline
\end{tabular}

Values are presented as mean \pm standard deviation or percent.

BMI: body mass index; ASA: American Society of Anaesthesiologists; Hb: hemoglobin; PT: prothrombin time; INR: international normalized ratio.

aBody temperature was defined as the first temperature measured using a digital axillary thermometer within 10 minutes of entry into the intensive care unit.

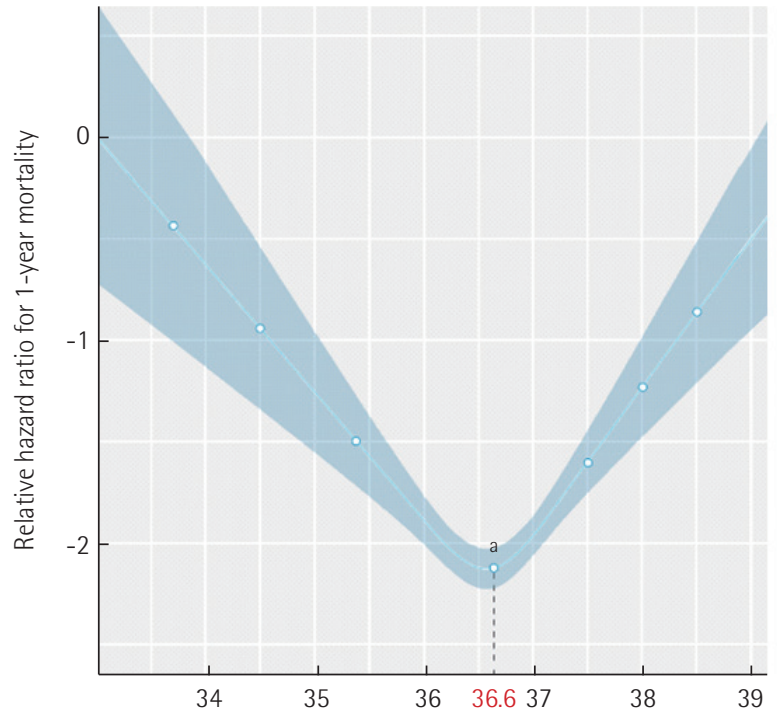

First postoperative body temperature in the $\mathrm{ICU}\left({ }^{\circ} \mathrm{C}\right)$

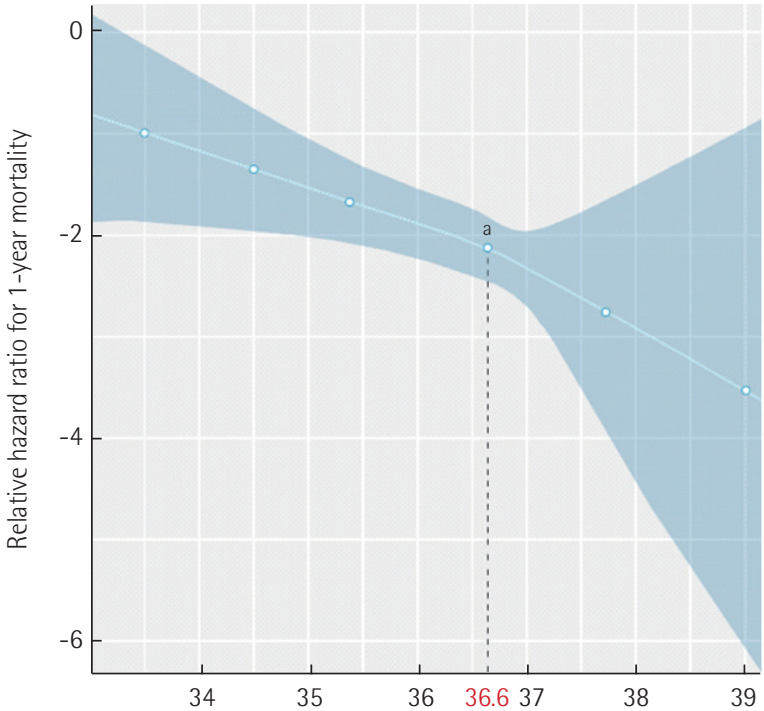

First postoperative body temperature in the $\mathrm{ICU}\left({ }^{\circ} \mathrm{C}\right)$

Figure 1. Restricted cubic splines between initial postoperative axillary temperature in the intensive care unit (ICU) and postoperative 1 -year mortality. The results are shown for (A) noncardiovascular surgery and (B) cardiovascular surgery. Body temperature was defined as

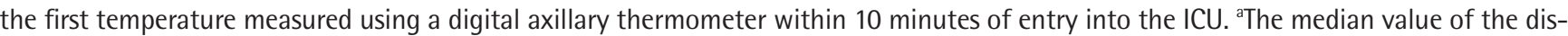
tribution of first postoperative body temperature in the ICU. 
Table 3. Multivariable regression model with restricted cubic splines for 1-year mortality after postoperative admission to the intensive care unit

\begin{tabular}{|c|c|c|c|c|c|c|c|c|c|}
\hline \multirow{2}{*}{ Variable } & \multicolumn{3}{|c|}{ All patients } & \multicolumn{3}{|c|}{ Noncardiovascular surgery } & \multicolumn{3}{|c|}{ Cardiovascular surgery } \\
\hline & Coefficient & SE & P-value & Coefficient & SE & P-value & Coefficient & SE & P-value \\
\hline Age (yr) & 0.032 & 0.004 & $<0.001$ & 0.030 & 0.004 & $<0.001$ & 0.053 & 0.015 & $<0.001$ \\
\hline BMI $\left(\mathrm{kg} / \mathrm{m}^{2}\right)$ & -0.119 & 0.015 & $<0.001$ & -0.121 & 0.016 & $<0.001$ & -0.107 & 0.054 & 0.049 \\
\hline Cancer (yes) & 1.353 & 0.109 & $<0.001$ & 1.425 & 0.116 & $<0.001$ & - & - & - \\
\hline Emergency surgery (yes) & 0.646 & 0.125 & $<0.001$ & 0.606 & 0.134 & $<0.001$ & 0.990 & 0.403 & 0.014 \\
\hline Body temperature: linear $\left(\leq 36.6^{\circ} \mathrm{C}\right)^{a}$ & -0.531 & 0.114 & $<0.001$ & -0.701 & 0.138 & $<0.001$ & -0.230 & 0.191 & 0.229 \\
\hline Body temperature: spline $\left(\geq 36.6^{\circ} \mathrm{C}\right)^{a}$ & 0.756 & 0.140 & $<0.001$ & 0.974 & 0.158 & $<0.001$ & - & - & - \\
\hline Albumin $(<3 \mathrm{~g} / \mathrm{dl})$ & 0.494 & 0.117 & $<0.001$ & 0.456 & 0.128 & $<0.001$ & 0.902 & 0.359 & 0.012 \\
\hline Creatinine (>1.3 mg/dl) & 0.857 & 0.134 & $<0.001$ & 0.765 & 0.147 & $<0.001$ & 1.390 & 0.358 & $<0.001$ \\
\hline Hemoglobin (g/dl) & -0.045 & 0.029 & 0.120 & -0.040 & 0.031 & 0.196 & -0.042 & 0.099 & 0.674 \\
\hline Platelet count $\left(<100 \times 10^{3} / \mu \mathrm{l}\right)$ & 0.429 & 0.150 & 0.004 & 0.518 & 0.165 & 0.002 & - & - & - \\
\hline PT $>1.3$ INR & 0.563 & 0.118 & $<0.001$ & 0.586 & 0.129 & $<0.001$ & 0.248 & 0.376 & 0.510 \\
\hline White blood cell $\left(>10 \times 10^{3} / \mu \mathrm{l}\right)$ & 0.228 & 0.106 & 0.031 & 0.245 & 0.112 & 0.029 & - & - & - \\
\hline
\end{tabular}

SE: standard error; BMI: body mass index; PT: prothrombin time; INR: international normalized ratio.

aody temperature was defined as the first temperature measured using a digital axillary thermometer within 10 minutes of entry into the intensive care unit.

$\geq 36.6^{\circ} \mathrm{C}$ : spline coefficient, $\left.0.974, \mathrm{P}<0.001\right)$. However, no significant trend was observed in the cardiovascular surgery group ( $\leq 36.6^{\circ} \mathrm{C}$ : linear coefficient, $-0.230, \mathrm{P}=0.229 ; \geq 36.6^{\circ} \mathrm{C}$ : spline coefficient, $-0.157, \mathrm{P}=0.710$ ) (Supplementary Table 1).

\section{DISCUSSION}

The present study revealed that 1-year mortality increased in a linear pattern when body temperatures decreased relative to median temperature at ICU admission and increased in a spline pattern when the temperatures increased relative to the median temperature. This trend was maintained in the noncardiovascular surgery group but was not observed in the cardiovascular surgery group. These findings are meaningful, as the multivariable logistic regression analysis with RCS used three knots without defining hypothermia and hyperthermia using specific cutoff values.

There are many possible explanations for increased mortality at relatively high and low body temperatures. First, the temperature measurements may reflect intraoperative hypothermia because they were measured immediately after surgery, and that state is relatively common and closely associated with adverse outcomes [12]. Second, hypothermia at ICU admission is predicted by several critical conditions, such as coagulopathy, excessive blood loss, acidosis, and shock [13]. However, the fact that some patients had hyperthermia immediately after surgery, despite receiving anaesthetic agents and undergoing surgical procedures that could induce hypothermia [14], suggests that they may have had infections [15].

Interestingly, this trend was limited to the overall group and the noncardiovascular surgery group and was not observed in the cardiovascular surgery group (with cardiopulmonary bypass). A possible explanation is that we did not exclude patients who underwent mild therapeutic hypothermia to reduce their metabolic demands and improve neurological outcomes after cardiovascular surgery [16]. In addition, patients who required sedation or depended on an extracorporeal membrane oxygenation device during the immediate postoperative period were included in the cardiovascular surgery group. Thus, the effects of complex variables make it difficult to detect a direct association between body temperatures during the immediate postoperative period and long-term outcomes in the cardiovascular surgery group. Therefore, given the relatively small sample size of the cardiovascular surgery group ( $\mathrm{n}=557)$, additional research is needed to examine this further.

The strengths of this study are the standardized definition of hypothermia $\left(\leq 36.6^{\circ} \mathrm{C}\right)$ and the use of digital axillary temperature. In contrast, previous studies have used various cutoff points to define hypothermia [10,17], which allow for precise evaluation of the association with mortality [9]. However, changes in the definition of hypothermia can eliminate noticeable changes in mortality (e.g., using $36^{\circ} \mathrm{C}$ and comparing $35.9^{\circ} \mathrm{C}$ vs. $36.1^{\circ} \mathrm{C}$, or $35.5^{\circ} \mathrm{C}$ vs. $36.5^{\circ} \mathrm{C}$ ). Furthermore, given 
that the range of normothermia is quite large [18], it may be preferable to analyze body temperature as a continuous variable. It is also possible that a digital axillary thermometer is less accurate than a tympanic thermometer for measuring core temperature [19], although a previous study indicated that the accuracies of both thermometers are similar [20]. However, digital axillary thermometers are superior in terms of ease-of-use, speed, durability, security, patient comfort, and cost [21]. Finally, tympanic thermometers can cause perforation of the tympanic membrane [22], and their use may be limited in patients who have undergone facial, ear, or brain surgery. Therefore, given patients' instability during their postoperative ICU stay, it may be more appropriate to use digital axillary thermometers.

The present study has several limitations. First, the singlecentre retrospective design is associated with known risks of bias. Second, the design did not consider any changes in clinical practice that had taken place during the study period. Third, only the first temperature measurement after ICU admission was used in the analysis, and we did not consider treatment or management processes (e.g., warming and therapeutic hypothermia). Fourth, the present study only evaluated a single method for measuring temperature.

In conclusion, the present study revealed increases in 1 -year mortality when body temperature increased or decreased (vs. $36.6^{\circ} \mathrm{C}$ ) among postoperative patients who were evaluated using a digital axillary thermometer within $10 \mathrm{~min}$ utes of ICU admission. However, this trend was not observed among patients who underwent cardiovascular surgery. This study suggests that postoperative temperature is associated with long-term mortality among patients admitted to the surgical ICU in the postoperative period.

\section{CONFLICT OF INTEREST}

No potential conflict of interest relevant to this article was reported.

\section{ORCID}

Jiwook Kim

https://orcid.org/0000-0002-3074-2705

Tak Kyu Oh https://orcid.org/0000-0002-4027-4423

Jaebong Lee https://orcid.org/0000-0002-9719-3376

Saeyeon Kim https://orcid.org/0000-0002-7329-2791

In-Ae Song

\section{AUTHOR CONTRIBUTIONS}

Conceptualization: JK, TKO, IAS. Data curation: SK. Formal analysis: JL. Methodology: JK, TKO, IAS. Writing - original draft: JK, TKO. Writing - review \& editing: IAS.

\section{SUPPLEMENTARY MATERIALS}

The online-only supplement data are available with this article online: https://doi.org/10.4266/acc.2019.00255.

\section{REFERENCES}

1. Vermeulen H, Storm-Versloot MN, Goossens A, Speelman P, Legemate DA. Diagnostic accuracy of routine postoperative body temperature measurements. Clin Infect Dis 2005; 40 : 1404-10.

2. Bush HL Jr, Hydo LJ, Fischer E, Fantini GA, Silane MF, Barie PS. Hypothermia during elective abdominal aortic aneurysm repair: the high price of avoidable morbidity. J Vasc Surg 1995;21:392-400.

3. Karalapillai D, Story D. Hypothermia on arrival in the intensive care unit after surgery. Crit Care Resusc 2008;10:116-9.

4. Slotman GJ, Jed EH, Burchard KW. Adverse effects of hypothermia in postoperative patients. Am J Surg 1985;149:495501.

5. Frank SM, Fleisher LA, Breslow MJ, Higgins MS, Olson KF, Kelly S, et al. Perioperative maintenance of normothermia reduces the incidence of morbid cardiac events: a randomized clinical trial. JAMA 1997;277:1127-34.

6. Kurz A, Sessler DI, Lenhardt R; Study of Wound Infection and Temperature Group. Perioperative normothermia to reduce the incidence of surgical-wound infection and shorten hospitalization. N Engl J Med 1996;334:1209-15.

7. Grocott HP, Mackensen GB, Grigore AM, Mathew J, Reves JG, Phillips-Bute B, et al. Postoperative hyperthermia is associated with cognitive dysfunction after coronary artery bypass graft surgery. Stroke 2002;33:537-41.

8. Kongsayreepong S, Chaibundit C, Chadpaibool J, Komoltri C, Suraseranivongse S, Suwannanonda $\mathrm{P}$, et al. Predictor of core hypothermia and the surgical intensive care unit. Anesth Analg 2003;96:826-33.

9. Karalapillai D, Story DA, Calzavacca P, Licari E, Liu YL, Hart GK. Inadvertent hypothermia and mortality in postoperative intensive care patients: retrospective audit of 5050 patients. Anaesthesia 2009;64:968-72.

10. Baucom RB, Phillips SE, Ehrenfeld JM, Muldoon RL, Poulose 
BK, Herline AJ, et al. Association of perioperative hypothermia during colectomy with surgical site infection. JAMA Surg 2015;150:570-5.

11. Marrie RA, Dawson NV, Garland A. Quantile regression and restricted cubic splines are useful for exploring relationships between continuous variables. J Clin Epidemiol 2009;62:5117.e1.

12. Sund-Levander M, Forsberg C, Wahren LK. Normal oral, rectal, tympanic and axillary body temperature in adult men and women: a systematic literature review. Scand J Caring Sci 2002;16:122-8.

13. Yi J, Lei Y, Xu S, Si Y, Li S, Xia Z, et al. Intraoperative hypothermia and its clinical outcomes in patients undergoing general anesthesia: national study in China. PLoS One 2017;12: e0177221.

14. Eddy VA, Morris JA Jr, Cullinane DC. Hypothermia, coagulopathy, and acidosis. Surg Clin North Am 2000;80:845-54.

15. Sessler DI. Temperature monitoring and perioperative thermoregulation. Anesthesiology 2008;109:318-38.

16. Pile JC. Evaluating postoperative fever: a focused approach. Cleve Clin J Med 2006;73 Suppl 1:S62-6.

17. Lewis ME, Al-Khalidi AH, Townend JN, Coote J, Bonser RS.
The effects of hypothermia on human left ventricular contractile function during cardiac surgery. J Am Coll Cardiol 2002;39:102-8.

18. Kiekkas P, Fligou F, Igoumenidis M, Stefanopoulos N, Konstantinou E, Karamouzos V, et al. Inadvertent hypothermia and mortality in critically ill adults: systematic review and meta-analysis. Aust Crit Care 2018;31:12-22.

19. Erickson RS, Kirklin SK. Comparison of ear-based, bladder, oral, and axillary methods for core temperature measurement. Crit Care Med 1993;21:1528-34.

20. Uslu S, Ozdemir H, Bulbul A, Comert S, Bolat F, Can E, et al. A comparison of different methods of temperature measurements in sick newborns. J Trop Pediatr 2011;57:418-23.

21. Rubia-Rubia J, Arias A, Sierra A, Aguirre-Jaime A. Measurement of body temperature in adult patients: comparative study of accuracy, reliability and validity of different devices. Int J Nurs Stud 2011;48:872-80.

22. Tabor MW, Blaho DM, Schriver WR. Tympanic membrane perforation: complication of tympanic thermometry during general anesthesia. Oral Surg Oral Med Oral Pathol 1981;51: 581-3. 
Kim J, et al. Postoperative Temperature and 1-Year Mortality

Supplementary Table 1. Results of univariable logistic regression with restricted cubic splines for 1-year mortality after postoperative admission to the intensive care unit

\begin{tabular}{|c|c|c|c|c|c|c|c|c|c|}
\hline \multirow{2}{*}{ Variable } & \multicolumn{3}{|c|}{ All patients } & \multicolumn{3}{|c|}{ Noncardiovascular surgery } & \multicolumn{3}{|c|}{ Cardiovascular surgery } \\
\hline & Coefficient & SE & P-value & Coefficient & SE & P-value & Coefficient & SE & P-value \\
\hline \multicolumn{10}{|l|}{ Body temperature ${ }^{a}$} \\
\hline Linear $\left(\leq 36.6^{\circ} \mathrm{C}\right)$ & -0.539 & 0.091 & $<0.001$ & -0.628 & 0.109 & $<0.001$ & -0.341 & 0.150 & 0.023 \\
\hline Spline $\left(\geq 36.6^{\circ} \mathrm{C}\right)$ & 0.799 & 0.106 & $<0.001$ & 0.909 & 0.120 & $<0.001$ & -0.157 & 0.421 & 0.710 \\
\hline
\end{tabular}

SE: standard error.

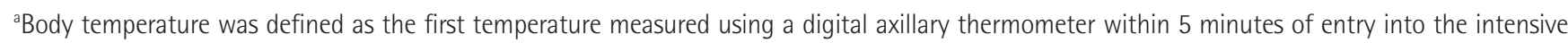
care unit. 